\title{
CONFERÊNCIA DAS EDIÇÕES DOS CADERNOS LÁGRIMAS, CADERNO FOTOCOPIADO 1 E DIÁRIO DE UM JOÃO NINGUÉM
}

\author{
$\underline{\text { Patricia Silva Pinto }^{1} \text {; Liliane Lemos Santana Barreiros }}{ }^{2}$ \\ 1. PROBIC/UEFS, Graduanda em Letras com Espanhol, Universidade Estadual de Feira de Santana, e-mail: \\ patriciasilvapinto@gmail.com \\ 2. Orientadora, Departamento de Letras e Artes, Universidade Estadual de Feira de Santana, e-mail: \\ lilianeuefs@uefs.com
}

PAlAVRAS-CHAVE: Edição. Cadernos. Eulálio Motta.

\section{INTRODUÇÃO}

O projeto de pesquisa Edição das obras inéditas de Eulálio Motta tem como objetivo editar e publicar as obras inéditas do autor Eulálio de Miranda Motta (19071988), detectadas por Barreiros (2009). O escritor baiano Eulálio Motta organizou um acervo que contém tipos de documentos. Na reunião documental distinguem-se quinze cadernos que compreendem laboratório do escritor e constituem o corpus fundamental do projeto de pesquisa. Conforme a metodologia aplicada pelo projeto, os documentos textuais são editados de acordo com o método da Crítica Textual em diálogo com a Crítica Genética.

O plano de trabalho intitulado "Conferência das edições dos cadernos Lágrimas, Caderno Fotocopiado 1 e Diário de um João Ninguém" tinha por objetivo inicial fazer a conferência das transcrições dos textos dos respectivos cadernos. No entanto, devido a extensão dos mesmos e a necessidade de editar alguns fólios do caderno Caderno Fotocopiado 1, não foi possível fazer a conferência dos cadernos Lágrimas e Diário de um João Ninguém. Desse modo, as atividades concentraram-se na edição e conferência do Caderno fotocopiado 1, utilizando-se da transcrição semidiplomática dos textos, passo inicial para qualquer trabalho filológico (SPINA, 1999; CAMBRAIA, 2005; BARREIROS, 2012),

Trata-se de uma fotocopia colorida e encadernada em espiral, com uma capa plástica azul transparente, contém 80 fólios escritos no reto e no verso, contendo textos sobre política, religião, compra e venda de imóveis, cartas e crônicas.

Para a conferência, foi utilizada a Crítica Textual com base no rigor lachmanniano método filológico esboçado pelo alemão Karl Lachmann, no final do século XIX, com intuito de suprir as lacunas concernentes às especificidades como a falta do texto original (BARREIROS, 2013).

O presente trabalho tem por objetivo a conferência das transcrições dos textos do caderno, Caderno Fotocopiado, na perspectiva de garantir a fidedignidade da edição, corrigindo os possíveis erros de transcrição dos textos, dando confiabilidade à pesquisa filológica, além de conferir a ficha de descrição dos cadernos, contribuir para o tratamento filológico da documentação do acervo do escritor.

O presente trabalho se faz importante por trazer uma contribuição que se soma aos estudos acerca das obras inéditas de Eulálio Motta, bem como a ampliação dos conhecimentos sobre o escritor baiano. 


\section{MATERIAL E MÉTODOS OU METODOLOGIA}

Editar um texto não é uma tarefa fácil, tampouco pode ser feita apressadamente como descreve Barreiros (2012). Se faz necessário ter conhecimento do código linguístico e os usos escribendis do autor, a história de sua transmissão e recepção, além das técnicas utilizadas para sua codificação. O método filológico da Critica Textual elaborado por Karl Lachmann compreende um número de procedimentos que têm por finalidade o estabelecimento do texto autoral, nesse caso em específico os textos de Eulálio Motta. O método lachmanniano foi elaborado para textos que não se dispunha do original (BARREIROS, 2013).

A conferência das edições dos cadernos lágrimas, caderno fotocopiado 1 trabalho foi executado a partir da Crítica Textual sob o rigor da metodologia Lachmann. Essa metodologia foi adotada tendo por finalidade não cometer erros, pois conforme Cambraia (2005) o erro em uma edição pode disseminar informações que se estabelecem na sociedade, dificultando a correção de equívocos e imprecisões. "É o filólogo responsável pelo texto crítico que traz ao conhecimento do público, com suas escolhas, seus comentários e estudos críticos" (SANTOS, 2015, p. 12).

O material revisado que compreende o Caderno fotocopiado 1 está organizado da seguinte maneira: fac-símile à esquerda e a transcrição à direita. Para o desenvolvimento da pesquisa, utilizou-se como referencial teórico o método filológico da Crítica Textual Moderna (SPINA, 1994; SPAGGIARI e PERUGI, 2004; CAMBRAIA, 2005) e os critérios e princípios de edição das obras inéditas de Eulálio Motta estabelecidos por Barreiros (2012; 2015), a saber:

a) Indica-se o numero do fólio; As linhas são numeradas de cinco em cinco à margem esquerda;

b) Os textos são transcritos em fonte Times New Roman padrão Word; de tamanho 11, alinhado à margem esquerda;

c) Transcreve-se o texto como se encontra no original;

d) São mantidos a ortografia, a acentuação, o uso de maiúsculas e a pontuação;

e) São utilizados símbolos para indicar trechos, palavras e letras ilegíveis; escritas fora da pauta;

f) São utilizadas e notas de pé de página para indicar informações complementares tais como: alternância da cor da tinta, emprego de símbolos e numeração de página, etc.

No processo de transcrição dos textos também foram empregados símbolos operadores da crítica genética, conforme critérios propostos por Barreiros (2012):

1. \{ \} seguimento riscado, cancelado;

2. $\{\dagger\}$ seguimento ilegível;

3. $\{\dagger\} / \backslash$ segmento ilegível substituído por outro legível na relação \{ilegível /legívell;

4. \{ \} / substituição por sobreposição, na relação \{substituído\} /substitutol;

5. \{ $\}[\uparrow]$ riscado e substituído por outro na entrelinha superior;

6. [ ] acréscimo no curso da linha;

7. [ $\uparrow]$ acréscimo na entrelinha superior;

8. [ $\downarrow]$ acréscimo na entrelinha inferior;

9. $[\uparrow\{\}]$ acréscimo na entrelinha superior riscado;

10. $[\uparrow\{\uparrow\}]$ acréscimo na entrelinha superior ilegível; 
11. $[\uparrow\{\uparrow\} / 】$ acréscimo na entrelinha superior ilegível e substituído por outro na sequência;

12. $[\downarrow\{\dagger\} / \backslash]$ acréscimo na entrelinha inferior ilegível e substituído por outro na sequência;

13. [*个] parte do texto localizada à margem superior indicada pelo autor através de seta, linha ou números remissivos;

14. / * / leitura conjecturada;

15. ( ) intervenção do editor (acréscimos e informações).

\section{RESULTADOS E/OU DISCUSSÃO (ou Análise e discussão dos resultados)}

O Caderno fotocopiado 1 constitui-se de uma reunião de textos manuscritos que tratam sobre determinadas temáticas como política, religião, compra e venda, avaliação de imóveis, entre outros. É formado por textos distribuídos em 80 fólios, escritos no reto e verso. Os escritos se apresentam em tipos textuais como: crônicas, cartas, relatos e listas de bens.

Os textos encontrados no Caderno fotocopiado 1 foram escritos entre os anos de 1950 a 1955, apresentam-se em bom estado de conservação. Apesar disso, durante a edição e conferência houve dificuldade na leitura da caligrafia do autor. Durante a realização do trabalho, observou-se que algumas palavras possuíam grafia diferente da atualidade.

Figura 1 - Transcrição do fólio 136 verso do Caderno fotocopiado 1

\begin{tabular}{|c|c|c|}
\hline \multirow{2}{*}{ Dresalo nurifor verenavio Sampano: } & & f. $68 \mathrm{v}$ \\
\hline & & [个Presado amigo Agenario Sampaio:] \\
\hline \multirow{9}{*}{ 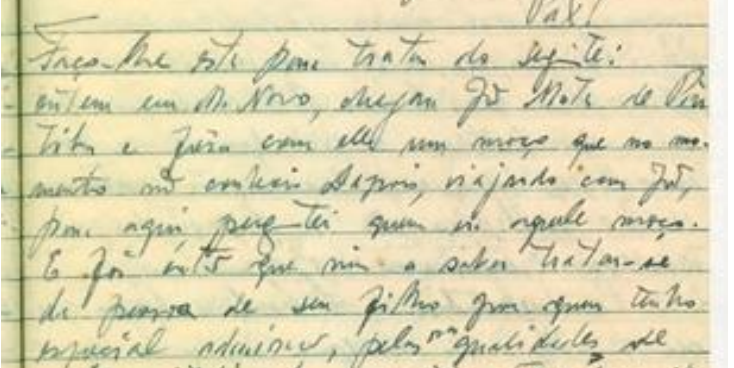 } & & [个Pax!] \\
\hline & & Faço - lhe este para tratar do seguinte: \\
\hline & & ontem em M. Novo, chegam João Mota de Piri- \\
\hline & 5 & tiba e fôra com ele um moço que no mo- \\
\hline & & mento não conhecia. Depois, viajando com João, \\
\hline & & foi que perguntei quem era aquele moço. \\
\hline & & E foi então que vim a saber tratar-se \\
\hline & & da pessoa de seu filho por quem tenho \\
\hline & 10 & especial admiração, pelas [ $\uparrow$ suas] qualidades $\{$,$\} de$ \\
\hline \multirow{5}{*}{ 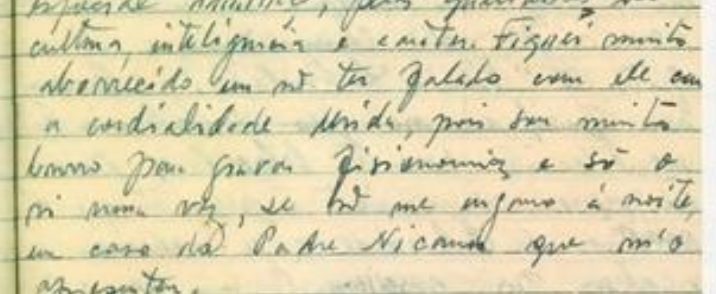 } & & cultura, inteligência e carater. Fiquei muito \\
\hline & & aborrecido em não ter falado com ele com \\
\hline & & a cordialidade devida, pois sou $n$ \\
\hline & 15 & vi uma vez, se não me engano á noite, \\
\hline & & em casa do Padre Nicano que m'o \\
\hline \multirow{9}{*}{ 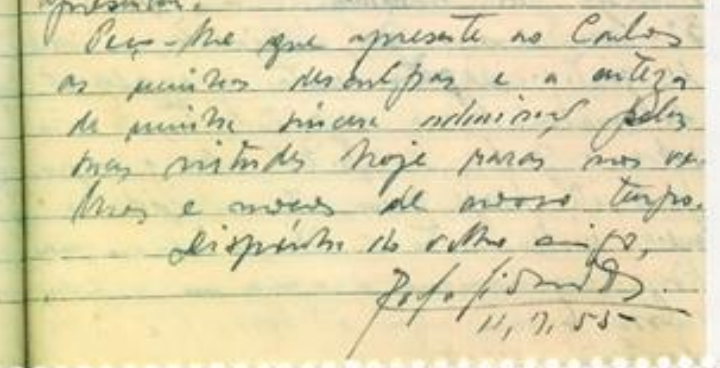 } & & apresentou. \\
\hline & & Peço - lhe que apresente no Carlos \\
\hline & & as minhas desculpas e a certeza \\
\hline & 20 & da minha sincera admiração pelas \\
\hline & & suas virtudes hoje raras nas ve- \\
\hline & & lhos e moços de \\
\hline & & Disp \\
\hline & & (assi \\
\hline & 25 & {$[\downarrow 11,7,55]$} \\
\hline
\end{tabular}

Fonte: Acervo de Eulálio Motta. 


\section{CONSIDERAÇÕES FINAIS}

O método filológico da Crítica Textual lachmanniano contribuiu de maneira significativa para a conferência da transcrição dos textos que compõem o Caderno Fotocopiado 1. Tomando por premissa o rigor na transcrição e na conferência da transcrição dos textos, os escritos foram organizados em arquivos digitais para integrar o banco de dados eletrônico, colaborando de maneira expressiva para a edição das obras literárias inéditas de Eulálio Motta. A escrita do autor mundonovense se debruça sobre variados temas que refletem as questões políticas e sociais da época. Assim, a conferência das transcrições possibilita estudos filológicos e literários bem como uma melhor compreensão dos textos em seus aspectos linguísticos, históricos e sociais.

\section{REFERÊNCIAS}

BARREIROS, Patrício Nunes. O Pasquineiro da Roça, a hiperedição dos panfletos de Eulálio Motta. Feira de Santana: UEFS Editora, 2015.

BARREIROS, Patrício Nunes. A relevância do dossiê arquivístico em edições digitais de documentos de acervos de escritores. Revista Internacional del Libro, Digitalización y Bibliotecas, v. 2, p. 20-33, 2014.

BARREIROS, Patrício Nunes. Clio: um diálogo com a musa nos bastidores da filologia. Philologus. Rio de Janeiro, v. 57, p. 45-63, 2013.

BARREIROS, Patrício Nunes. Sonetos de Eulálio Motta. Feira de Santana: UEFS Editora, 2012.

BARREIROS, Patrício N. A oficina do escritor e os projetos editorais de Eulálio de Miranda Motta. In: Anais do XIII Congresso Nacional de Linguística e Filologia. Rio de Janeiro: EDUERJ, v. XIII, n. 04, 2009, p. 1465-1480.

CAMBRAIA, César Nardelli. Introdução à crítica textual. São Paulo: Martins Fontes, 2005.

SANTOS, R. B. Estudos filológicos na contemporaneidade: relato de uma experiência. Inventário (Universidade Federal da Bahia. Online), No 17, dez 2015, Salvador/Ba.

SPAGGIARI, Barbara; PERUGI, Maurizio. Fundamentos da crítica textual. Rio de Janeiro: Lucerna. 2004.

SPINA, Segismundo. Introdução à edótica: crítica textual. 2. ed. rev. e atual. São Paulo: ArsPoetica/EDUSP, 1994. 